\title{
Generation and characterization of mice with a conditional null allele of the $\mathrm{HtrA4}$ gene
}

\author{
$\mathrm{JU} \mathrm{LIU}^{1,2}$, YAN LI ${ }^{3}$ and JOSEPHINE $\mathrm{HOH}^{1}$ \\ ${ }^{1}$ Department of Epidemiology and Public Health, Yale University, New Haven, CT 06520, USA; \\ ${ }^{2}$ Medical Research Center; ${ }^{3}$ Children's Health Care Center, Shandong Provincial Qianfoshan Hospital, \\ Shandong University, Jinan, Shandong 250014, P.R. China
}

Received April 23, 2015; Accepted August 11, 2015

DOI: $10.3892 / \mathrm{mmr} .2015 .4291$

\begin{abstract}
High temperature requirement factor A4 (HtrA4) is a member of the HtrA family of serine peptidases involved in regulating protein-protein interactions. Little is known regarding the function of HtrA4 in humans and in mouse models. To gain insights into the role of HtrA4 in vivo, mice were generated with a conditional null allele of HtrA4 by flanking exons 4, 5 and 6 with loxP sites. Cre-mediated recombination, using a ubiquitously active Rosa26-Cre line, resulted in the deletion of the floxed region in the mouse genome. Mice homozygous for the recombinant allele $\left(\mathrm{HtrA4}^{-/}\right)$were viable, fertile and appeared to be normal. The HtrA4 protein was detectable in coronary vessels and in the placenta. However, the loss of HtrA4 affected neither the basic heart nor placental functions. These mice, featuring a conditional null allele of HtrA4, may provide a valuable tool to investigate the role of HtrA4 in development and pathogenesis of coronary heart disease and preeclampsia.
\end{abstract}

\section{Introduction}

The mammalian high temperature requirement factor A4 (HtrA4) is one of four members of the HtrA family of serine proteases. First identified in bacteria as DegP (1), homologs of the HtrA family have been identified in vertebrates, invertebrates and humans (2). All HtrAs share one or multiple highly conserved C-terminal PDZ domains, which bind target proteins and regulate protein-protein interactions, whereas

Correspondence to: Professor Ju Liu, Medical Research Center, Shandong Provincial Qianfoshan Hospital, Shandong University, 16766 Jingshi Road, Jinan, Shandong 250014, P.R. China

E-mail: ju.liu@sdu.edu.cn

Professor Josephine Hoh, Department of Epidemiology and Public Health, Yale University, 60 College Street, New Haven, CT 06520, USA

E-mail: josephine.hoh@yale.edu

Key words: high temperature requirement factor A 4, heart, placenta, conditional null allele, Cre/loxP the $\mathrm{N}$-terminus is variable and contains the signal and regulatory sequences (3). Members of the HtrA family are involved in a variety of human diseases $(4,5)$. The most important previous study to date was a genome-wide association study, which identified a marked genetic linkage between specific overexpressed variants of the HtrAl gene and the wet form of age-associated macular degeneration (6). HtrA1, 2 and 3 have also been implicated in osteoarthritis, cancer, Alzheimer's disease, Parkinson's disease and muscular dystrophy (7-14).

Among the HtrA family members, HtrA4 has rarely been investigated. The HtrA4 protein is predicted to be an oligomeric chaperone protease, which degrades misfolded secretory proteins (15). HtrA4 may exert its action by cleaving within the $\beta$-actin sequence to inhibit its ability to form insoluble fibers (16). The transcripts of HtrA4 were upregulated in the placenta of patients with severe pre-eclampsia (17). The role of HtrA4 remains to be fully elucidated in mice. Mouse HtrA4 is a protein of 483 amino acids, which shares $68.18 \%$ similarity in amino acid sequence with its human homolog. The mouse HtrA4 and HtrA1 proteins share a similar domain structure (4). The mouse HtrA4 gene is located on chromosome 8 (at $13.70 \mathrm{cM}$ ), and consists of nine exons. Exon 1 codes for the insulin-growth-factor-binding and Kazal protease inhibitor domains, exons 3-6 code for a trypsin-like catalytic domain, and exons 7-9 code for the PDZ domains.

The present study aimed to further characterize the cellular functions of HtrA4 in vivo, by generating an HtrA4 conditional allele in mice, which allows the inactivation of HtrA4 through Cre-mediated recombination in a cell-type-specific manner. In addition, the phenotype of the HtrA4 knockout mice was characterized.

\section{Materials and methods}

Animals. The mice with an HtrA4 floxed allele were generated by Ozgene (Bentley, Australia). Briefly, a flippase recognition target (FRT)-flanked phosphoglycerate kinase I (PGK)-neomycin cassette was inserted downstream of exon 5 of the HtrA4 gene. The loxP sites were inserted upstream of exon 4, downstream of exon 6, and in between exon 5 and the selection cassette. The construct was incorporated into the genomic DNA of embryonic stem (ES) cells from C57BL/6J mice by electroporation using GenePulser (Bio-rad 
A

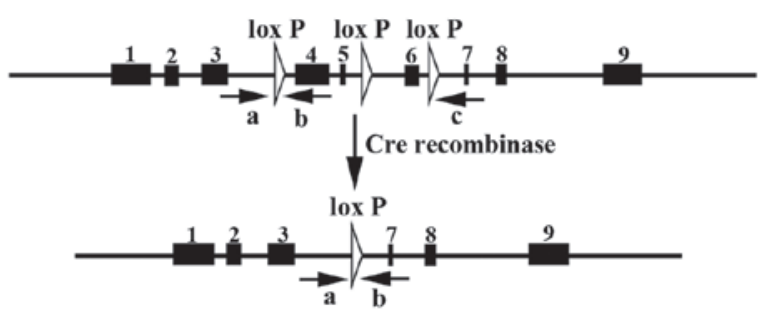

B

C

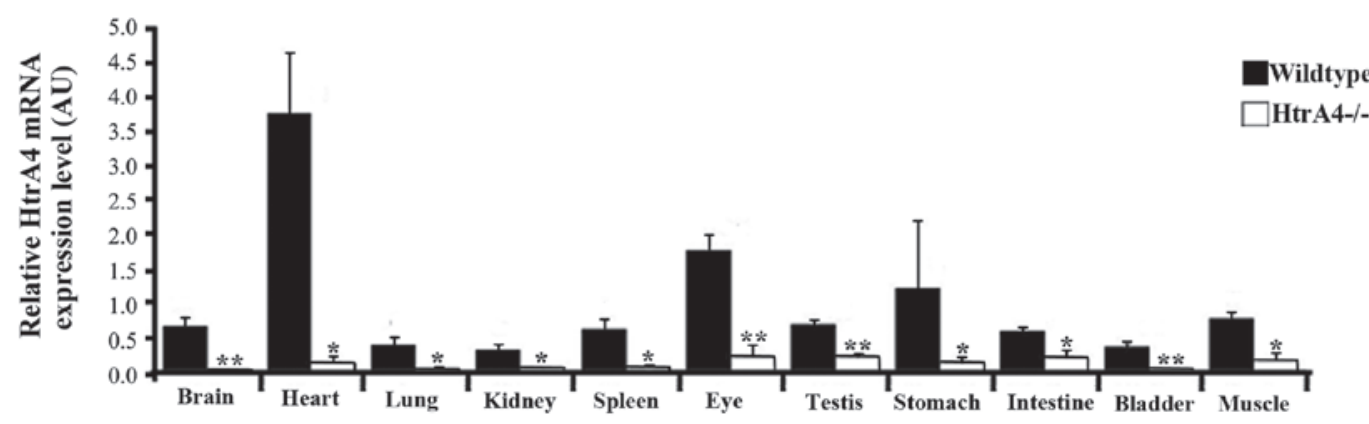

Figure 1. Validation of mice harboring the HtrA4 conditional null allele. (A) Schematic representation of the floxed and deleted alleles of $H t r A 4$ conditional null mice. The exons are presented as rectangles. A total of three loxP sites (white triangles) were inserted between exons 3/4,5/6 and 6/7. The floxed sequences were deleted following Cre excision. The horizontal arrows refer to the primers used for genotyping. (B) Polymerase chain reaction genotyping of $H t r A 4$ conditional null mice was performed. Primers a, b and c were used together for genotyping the tissue samples from the mice. HtrA4 ${ }^{+/}$mice were obtained by crossing $\mathrm{HtrA4}^{+} /$flox with Rosa26-Cre mice, and $\mathrm{HtrA}^{-/}$mice were obtained by intercrossing the $\mathrm{HtrA}^{+/-}$mice. Primers a and b produced a $311 \mathrm{bp}$ band for the wild-type allele, and a $354 \mathrm{bp}$ band for the HtrA4 floxed allele. Primers a and c produced a 534 bp band for a complete HtrA4 knockout allele. (C) Reverse transcription-quantitative polymerase chain reaction of the gene expression of $H$ trA4 in organs from wild-type and $H$ trA4 $4^{-\%}$ mice. The data are presented as the mean \pm standard error of the mean of three individual mice of the identical genotype $\left({ }^{*} \mathrm{P}<0.05\right.$ and ${ }^{* *} \mathrm{P}<0.01$, compared with the wild-type. HtrA4, high temperature requirement factor A4.

Laboratories Inc., Hercules, CA, USA) at $230 \mathrm{~V} / 500 \mu \mathrm{F}$ and subsequent selection. The targeted ES cells were injected into C57BL/6J blastocysts, and the aggregates were transferred into the uterus of recipient mice to produce chimeric mice. The chimeric mice were crossed with $\mathrm{C} 57 \mathrm{BL} / 6 \mathrm{~J}$ mice to generate $H$ trA4 ${ }^{+/ \text {flox-neo }}$ mice, which were bred with Rosa26-FlpE mice (provided by Ozgene) to remove the FRT-flanked PGK-neo cassette. The $H t r A 4^{+/ \text {flox }}$ mice were subsequently crossed with Rosa26-Cre mice to create an $\mathrm{HtrA} 4$ null allele. All mice were maintained on a C57BL/6J background. The animals (equal male to female ratio) were housed in separate cages at $21 \pm 1^{\circ} \mathrm{C}$ with a $12 \mathrm{~h}$ light/dark cycle with access to water and standard rodent pellets, in a conventional, pathogen-free facility at Yale University School of Medicine (New Haven, CT, USA). The present study and all experiments were performed in accordance with the guidelines issued by the Institutional Animal Care and Use Committee at Yale University (New Haven, CT, USA). The genomic DNA was digested with $S c a I$ restriction enzyme (New England Biolabs, Ipswich, MA, USA) and separated by electrophoresis in $0.8 \%$ agarose gel (Calbiochem, San Diego, CA, USA) for $12 \mathrm{~h}$ prior to Southern blot analyses. The following probes were used for Southern blot analysis of the ES cell clones and HtrA4 alleles in mice: The 3' probe, a 537 bp polymerase chain reaction (PCR) product targeting the genome sequence beyond the 3' end of the HtrA4 gene (primers: Forward, 5'-TGGTGTCACTGGGTCTCCTTA AAGC-3' and reverse, 5'-AGGGTTAGATCGGGATGTTTT AGGG-3'); the en probe, a 695 bp PCR product targeting genomic sequence on exon 8 (PCR primers: Forward, 5'-AACCAGATGGGGAAGAGATAGGCTC-3' and reverse, 5'-CAGAtGCAGATGCAATACAAGCTGC-3'). Primers used for PCR genotyping of the HtrA4 alleles as follows: Primer a, 5'-GCTGGAGTTAGAGGTGGTTGTGGAC-3' (forward); primer b, 5'-CAGGGAGATGGTTTAGAACAG TGG-3' (reverse); and primer c, 5'-TGCCTGTAAATGGAA AGCATGA-3' (reverse). All primers were obtained from Yale DNA Analysis facility, New Haven, CT, USA).

Gene expression analysis. The relevant tissues were collected from age and sex-matched mice of the wild-type and $\mathrm{HtrA4}^{-/-}$genotypes following intra-cardiac perfusion with cold phosphate-buffered saline (PBS). The tissues were snap frozen and homogenized in liquid nitrogen using a mortar and pestle. The homogenized tissues were incubated with TRIzol (Invitrogen; Thermo Fisher Scientific, Inc., Grand Island, NY, USA) for 30 min on ice, and total RNA was extracted using an RNeasy kit (Qiagen, Hilden, Germany) with optional DNase I treatment (Qiagen) according to the manufacturer's instructions. cDNA synthesis was conducted using the RevertAid First strand cDNA Synthesis kit (Thermo Fisher Scientific, Inc.) following the manufacturer's instruments. Reverse transcription-quantitative (RT-q)PCR was performed by the qPCR facility of Mt. Sinai School of Medicine (New York, NY, USA) with the following thermocycling conditions: $50^{\circ} \mathrm{C}$ for $2 \mathrm{~min}$ and $95^{\circ} \mathrm{C}$ for $2 \mathrm{~min}$, followed by 40 cycles of $95^{\circ} \mathrm{C}$ for $15 \mathrm{~s}$, and $60^{\circ} \mathrm{C}$ for $1 \mathrm{~min}$. The RNA levels were normalized against the endogenous control, gene mouse $\beta$-actin. The primers used were: $m H$ trA4, 5'-CTT GGATGGCGACGTGATTGGT-3' and 5'-TCTGCAAAGGGG CCTTGCCTT-3'; $\beta$-actin, 5'-AGGTGACAGCATTGCTTC TG-3' and 5'-GCTGCCTCAACACCTCAAC-3'. All reactions were performed in triplicate and a two-tailed t-test was used to determine statistical significance. 
A

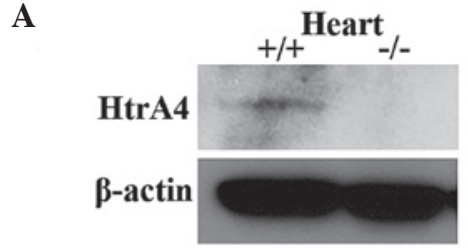

C

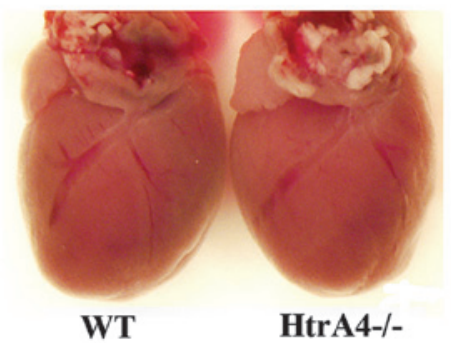

D

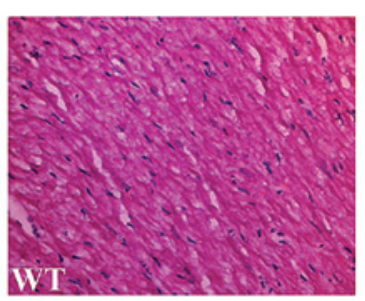

E

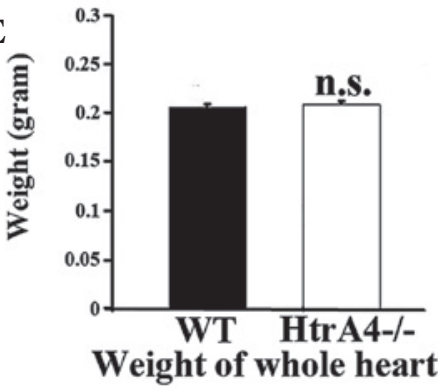

B
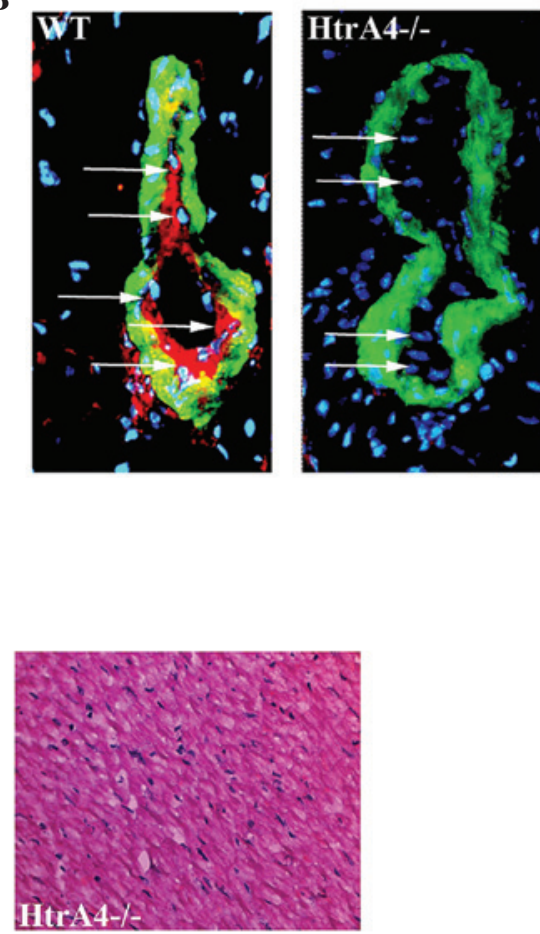

F

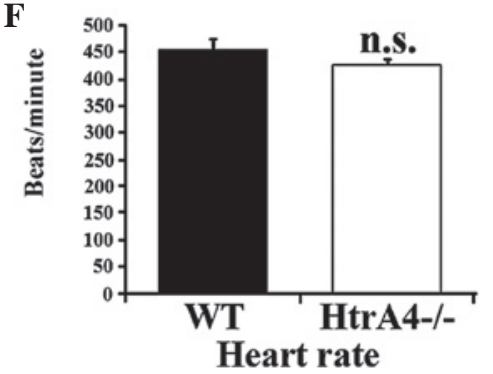

Figure 2. Expression of HtrA4 in the mouse heart. (A) Immunoblots were performed to determine the protein expression levels of HtrA4 and $\beta$-actin in heart extracts from WT and $H t r A 4^{-/}$mice. (B) Immunofluorescence staining of HtrA4 and $\alpha$-smooth muscle actin on cardiac tissue sections from WT and $H$ trA4 ${ }^{-/}$ mice was performed. Arrows indicate endothelial cells (magnification, x60). (C) Images of the heart from a 3-month-old HtrA4 ${ }^{-/}$mouse and its WT littermate were captured. (D) Hematoxylin and eosin staining of a cardiac tissue section from WT and HtrA4 ${ }^{-/}$mice (magnification, $\mathrm{x} 10$ ) was performed. (E) The weight of the hearts from 3-month-old WT and HtrA $4{ }^{-/}$mice were plotted in a histogram $(\mathrm{n}=6 ; \mathrm{P}=0.40)$. (F) The heart rates in beats/min of the 3-month-old WT and $\mathrm{HtrA4}^{-/}$mice were compared $(\mathrm{n}=15 ; \mathrm{P}=0.17)$. n.s., non-significant; WT, wild-type; HtrA4, high temperature requirement factor A4.

Immunohistochemistry. The mouse tissues were snap-frozen and embedded in optimal cutting temperature compound (Tissue-Tek; Miles, Inc., Elkhart, IN, USA), followed by serial sectioning at $6 \mu \mathrm{m}$. The tissue sections were cut at $6 \mu \mathrm{m}$ using a Leica CM1850 cryostat (Leica Microsystems $\mathrm{GmbH}$, Wetzlar, Germany) were air-dried and fixed in cold acetone for $2 \mathrm{~min}$ at room temperature. Following washing in PBS, the tissue sections were blocked for $15 \mathrm{~min}$ in $1 \%$ BSA in PBS. The slides were incubated with polyclonal goat anti-HtrA4 antibody (1:40; cat. no. sc-87773; Santa Cruz Biotechnology, Inc., Santa Cruz, CA, USA) overnight at $40^{\circ} \mathrm{C}$. The tissue sections were washed three times and were incubated for 30 min with Texas Red conjugated rabbit anti-goat immunoglobulin (1:250; cat. no. TI-5000; Vector Laboratories, Burlingame, CA, USA). Following washing, the slides were mounted in VECTASHIELD ${ }^{\circledR}$ mounting medium, containing 4',6-diamidino-2-phenylindole (Vector Laboratories) and were visualized under a Zeiss Axio Imager M1 fluorescence microscope (Zeiss, Jena, Germany). The tissue sections from $\mathrm{HtrA}^{-/-}$mice were used as a negative control.

Echocardiography. Echocardiograms were obtained for lightly anesthetized mice (1\% isofluorane inhalation) using a Micro-Ultrasounds instrument (Vevo 770 Imaging system; Visual Sonics, Inc., Toronto, ON, Canada). Enlarged two-dimensional views were used to determine a short-axis plane at the level of the papillary muscles and the M-mode was obtained at this level. Measurements were obtained using the Vevo 770 analysis software.

Western blotting. Mouse tissues were harvested from 5-month-old $\mathrm{HtrA4}^{-/-}$mice and their control littermates following intra-cardiac perfusion with cold PBS. The tissues were lysed in radioimmunoprecipitation assay buffer (EMD Millipore, Billerica, MA, USA), supplemented with protease inhibitor cocktails (Roche Diagnostics, Mannheim, Germany), and the protein concentrations were measured by Bradford 


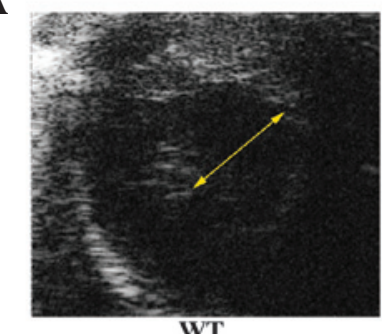

WT

C

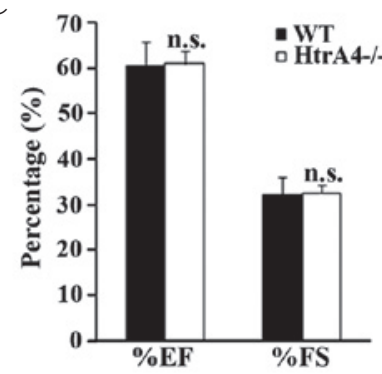

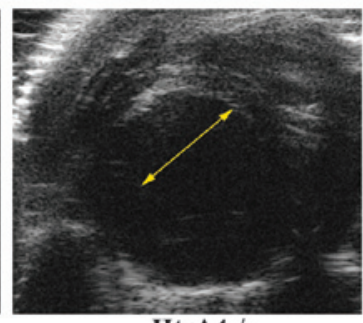

HtrA4--
B

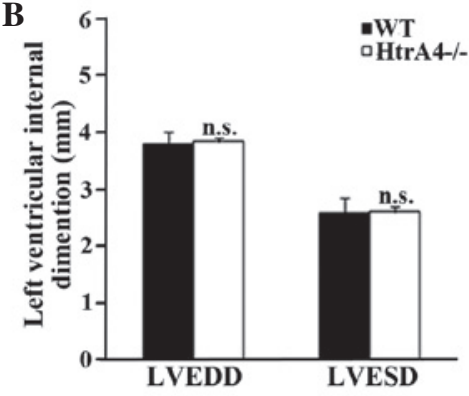

D

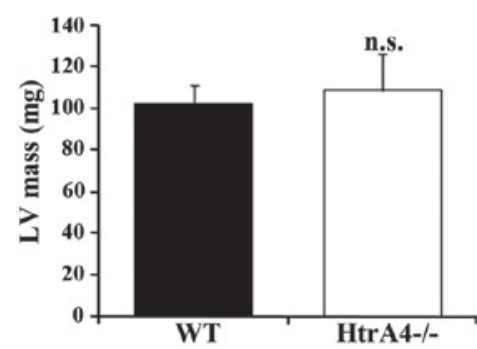

$\mathbf{E}$

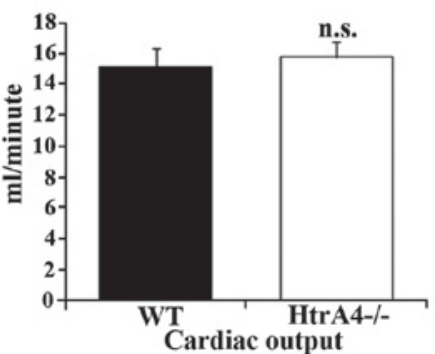

Figure 3. Echocardiographic analysis of the cardiac function of $H t r A 4^{-/}$mice. (A) Short-axis echocardiography demonstrated that the diameters of the left ventricles of the WT and HtrA4 ${ }^{-/}$mice were similar. The arrows show the size of the intraventricular diameters during diastole. (B) The LVEDD and LVESD of the left ventricles of the WT and $\mathrm{HtrA4}^{-/}$mice were measured ( $\mathrm{n}=6 ; \mathrm{P}=0.73$ and $\mathrm{P}=0.55$, for LVEDD and LVESD, respectively). (C) The EF and FS of the left ventricles of WT and $\mathrm{HtrA}^{-/}$mice were determined ( $\mathrm{n}=6 ; \mathrm{P}=0.39$ and $\mathrm{P}=0.34$, for \%EF and \%FS, respectively). (D) The masses of the left ventricle from the WT and $\mathrm{HtrA4}^{-/}$mice were measured and corrected by echocardiography $(\mathrm{n}=10 ; \mathrm{P}=0.33)$. (E) The cardiac output of the WT and $H t r A 4^{-/}$mice was determined ( $\mathrm{n}=9 ; \mathrm{P}=0.61)$. The results of these experiments were n.s. comparing WT with HtrA4 ${ }^{-/}$mice. EF, ejection fraction; FS, fractional shortening; LVEDD, left ventricular end diastolic diameter; LVESD, left ventricular end systolic diameter; HtrA4, high temperature requirement factor A4; n.s., non-significant; WT, wild-type.

assay (Bio-Rad Laboratories, Inc.) using a Bio-Rad 415 Visible Spectrophotometer (Bio-Rad Laboratories, Inc.). The lysates were separated using a 12\% Mini-protean TGX gel (Bio-Rad Laboratories, Inc.) and electroblotted onto polyvinylidene fluoride membranes (EMD Millipore). The membranes were blocked with $5 \%$ non-fat milk and were incubated overnight at $4{ }^{\circ} \mathrm{C}$ with goat anti-HtrA4 antibody (1:500; Santa Cruz Biotechnology, Inc.). Following washing, the membranes were probed with horseradish peroxidase-conjugated rabbit anti-goat secondary antibody (1:2,500; cat. no. sc-2768; Santa Cruz Biotechnology, Inc.). Western blotting signals were detected by enhanced chemiluminescence (Thermo Fisher Scientific) and exposed on X-ray films. The membranes were stripped using Mild Antibody Stripping Solution (EMD Millipore) and reblotted with mouse anti- $\beta$-actin antibody (1:10,000; Sigma-Aldrich, St. Louis, MO, USA) as a loading control.

Statistical analysis. The data are expressed as the mean \pm standard error of the mean. The statistical difference between two groups was evaluated using a two-tailed Student's t-test. All statistical analyses were performed using SPSS 17.0 (SPSS Inc., Chicago, IL, USA). P $<0.05$ was considered to indicate a statistically significant result.

\section{Results}

Generation of a conditional null allele of the HtrA4 gene in mice. The targeting construct was generated by flanking exons 4, 5 and 6 with loxP sites (Fig. 1A). Upon Cre excision, these three exons were removed and translation was terminated. A PGK-neo selection cassette, flanked by FRT sites, was inserted between exons 5 and 6. Exons 1-3 were preserved, as their transcripts were overlapping with a non-coding mRNA transcript of the Plekha2 gene. The targeting construct was linearized with $A c l$ I and introduced into the Bruce 4 ES cell line by electroporation. Following neomycin selection and Southern blot analysis, two ES cell clones with the correct integration were identified. These ES cell clones were injected into blastocysts in order to develop chimeras, and each cell exhibited a successful germline transmission of the HtrA4 conditional allele, which is termed HtrA4 flox-neo. To produce the HtrA4 $4^{f l o x}$ allele, HtrA4 $4^{f l o x-\text { neo/+ }}$ mice were bred with Flp deleter transgenic mice to remove the FRT-flanked PGK-neo cassette. The presence of all alleles was confirmed by Southern blotting (data not shown).

Confirmation of Cre-mediated excision of the HtrA4 gene in mice. To assess the in vivo excision of the HtrA4 flox allele, the HtrA4 $4^{\text {flox/+ }}$ mice were bred with Rosa26-Cre transgenic mice to delete the floxed region (18), generating the HtrA4 deletion mutants (Fig. 1A). The complete deletion of exons 4-6 was demonstrated by RT-qPCR, thereby confirming the effectiveness of the Cre excision (Fig. 1B). The HtrA4 ${ }^{\text {flox } /+}$;Rosa26-Cre mice were crossed with $\mathrm{C} 57 / \mathrm{B} 6$ mice to obtain $\mathrm{HtrA}^{+/-}$mice lacking the Rosa26-Cre transgene. $\mathrm{HtrA4}^{+/-}$mice were intercrossed to obtain mice homozygotes of HtrA4 deletion $\left(\mathrm{HtrA4}^{-/-}\right.$; Fig. 1B). The HtrA4 $4^{-/}$mice exhibited normal growth, without any obvious phenotypic differences. Among the surviving pups of the interbreeding of $\mathrm{HtrA4}^{+/-}$mice, 


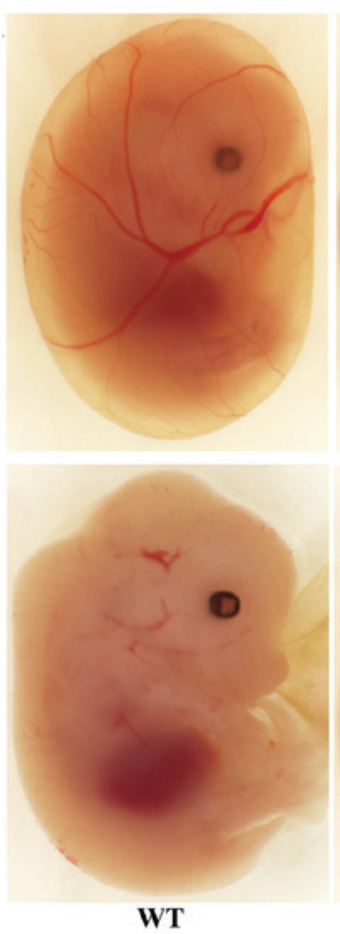

WT
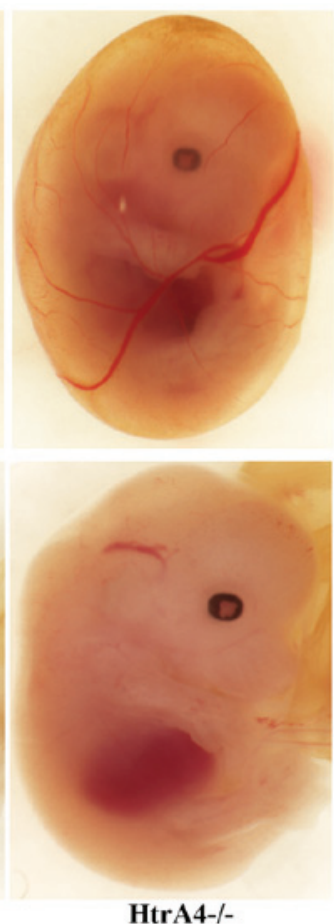

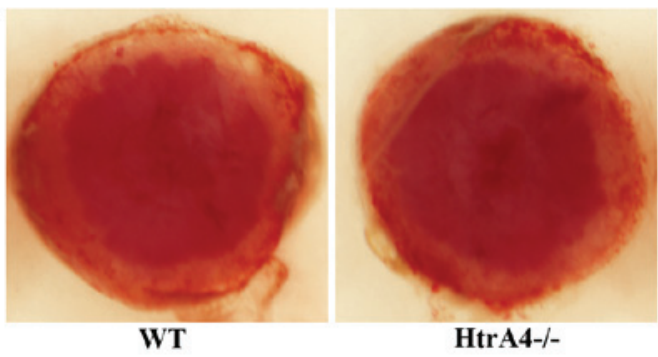

C
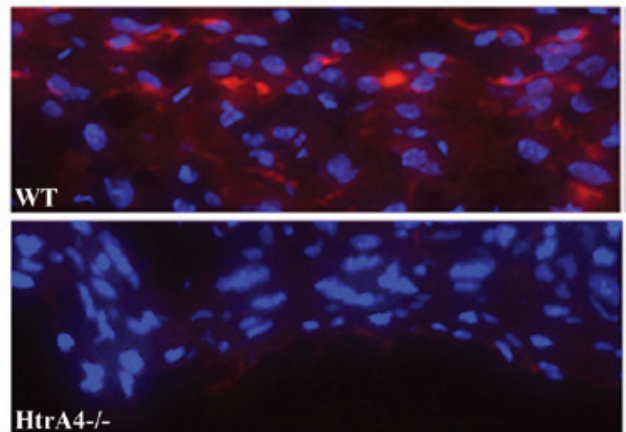

E

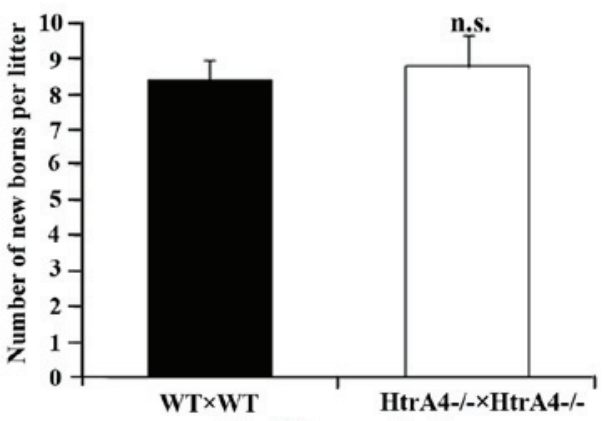

Fertility examination

Htrif 4 (n)

D

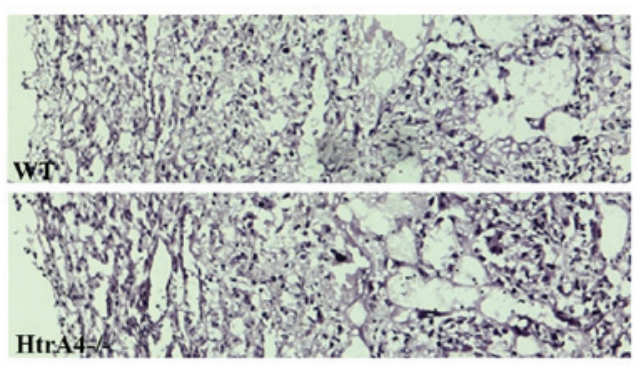
and $\mathrm{HtrA}^{-\%}$ embryo/HtrA4 ${ }^{-\%}$ mother are illustrated. (C) Immunofluorescence staining of HtrA4 in the mouse placenta of E13.5 WT embryo/WT mother and the $\mathrm{HtrA}^{-/}$embryo/HtrA4 ${ }^{-/}$mother are shown (magnification, x20) The red coloration represents the staining taken up by HtrA4. (D) Hematoxylin and eosin staining of of the mouse placenta of E13.5 WT embryo/WT mother and HtrA4 $4^{-/}$embryo/HtrA4 ${ }^{-/}$mother (magnification, $\mathrm{x} 10$ ) was performed. (E) The fertility of the WT/WT and HtrA $4^{-/} / \mathrm{HtrA} 4^{-/}$-crossed mice was examined. Each bar represents the mean \pm standard error of the number of pups per litter from intercrossing of wild-type and $H t r^{-/}{ }^{-2}$ mice $(\mathrm{n}=15, \mathrm{P}=0.72)$. n.s., non-significant;. WT, wild-type; HtrA4, high temperature requirement factor A4.

the ratio of the identified $H \operatorname{trA} 4^{-/}$genotype was no less than the expected Mendelian ratio, suggesting a lack of HtrA4 deletion-associated embryonic or neonatal lethality. To examine the expression pattern of HtrA4 and to confirm the loss of transcription of the HtrA4 gene in the $\mathrm{HtrA4}^{-/}$mice, the total mRNA was extracted from 11 organs (brain, heart, lung, kidney, spleen, bladder, eye, testis, stomach, intestine and skeletal muscle) from the mice and the level of transcription of the HtrA4 gene was determined by RT-qPCR using primers, which were targeted to the floxed region. In wild-type mice, HtrA4 was expressed at a low level in the majority of organs, with the exception of the heart (Fig. 1C). HtrA4 transcription was absent in tissues from the $\mathrm{HtrA4}^{-/}$mice (Fig. 1C).

Morphology and function of the HtrA4-/- mouse heart. The proteins from mouse tissues were extracted for western blot analysis. Among the 11 organs examined, the HtrA4 protein was only detected in the heart, which is consistent with the results from the mRNA analysis (Fig. 2A). The HtrA4 protein expression pattern was further assessed by immunofluorescence using an antibody targeting the C-terminus of the HtrA protein, together with an antibody against $\alpha$-smooth muscle actin, the marker for vascular smooth muscle cells. Consistent with the Western blotting results, only the heart revealed a detectable level of protein expression in the coronary vessels, which was absent in the hearts of the $\mathrm{HtrA}^{-/-}$mice (Fig. 2B). The expression of HtrA4 was restricted in the endothelial cells lining the inside layers of the smooth muscle cells (Fig. 2B). Therefore, the Cre-excised allele represented a null allele of HtrA4. Upon the loss of HtrA4, the size, weight and tissue morphology of the heart, and the heart rate (in beats/min) were demonstrated to be unaffected (Fig. 2C-F). 
Subsequently, the pumping action of the mouse heart was examined by echocardiography. The diameters of the left ventricle were measured at the papillary muscle level (Fig. 3A). The left ventricular end diastolic and end systolic diameters were similar in the wild-type and $\mathrm{HtrA4}^{-/}$mice (Fig. 3B). As shown in Fig. 3C, the fractional shortening and ejection fraction, which are major indicators for heart function, were not affected in the heart of the $\mathrm{HrA}_{\mathrm{A}} 4^{-/}$mice. In addition, the mass of the left ventricles and cardiac output of the HtrA $4^{-/}$mice were also similar to the wild-type mice (Fig. 3D and E). Therefore, the loss of HtrA4 failed to affect the morphology or function of the heart.

Morphology and function of the HtrA4 $4^{-/}$mouse placenta. The embryonic development of the $\mathrm{HtrA4}^{-/}$mice was analyzed. At embryonic day 13.5 , the $H t r A 4^{-/}$embryos, including the yolk sacs, exhibited a similar developmental pattern compared with their wild-type littermates (Fig. 4A). No HtrA4 expression was detectable by immunofluorescence at this stage of embryonic development, including in the embryonic heart. The HtrA4 transcript has been detected in human placenta (GenBank accession no. BC057765), therefore, the placenta of wild-type females with wild-type embryos and $\mathrm{HtrA4}^{-/-}$females with $\mathrm{HtrA}^{-/}$embryos were examined. The macroscopic morphology of the wild-type and $\mathrm{HtrA4}^{-/}$placentas was similar (Fig. 4B). A positive staining of HtrA4 was observed only on the decidual layer of the placenta of wild-type mice, and not on the $\mathrm{HtrA4}^{-1}$ placenta (Fig. 4C). Concerning the sections with hematoxylin and eosin staining, $\mathrm{HtrA4}^{-/-}$placentas demonstrated normal tissue structure and cell morphology (Fig. 4D). In addition, intercrossing of the $\mathrm{HtrA}_{4}{ }^{--}$mice produced a similar number of offsprings from each litter as the intercrossing of wild-type mice (Fig. 4E), indicating a normal placental function.

\section{Discussion}

The HtrA family of proteins perform vital roles in physiological processes, including apoptosis and cell signaling $(15,19)$. Previously, HtrA proteins 1, 2 and 3 were identified as potential drug targets for the treatment of cancer and neurodegenerative disorders $(4,5,19)$. Although the protein structure of HtrA4 is similar to the other three family members, HtrA4 has received little attention. In the present study, a conditional null HtrA4 allele in mice was successfully generated, and the phenotype of the HtrA4-deficient mice was characterized.

Although the gene inactivation of $\mathrm{HtrA4}^{-/}$was successfully achieved, no obvious differences in the phenotype between $\mathrm{HtrA}^{-/}$adult mice and embryos was identified in the present study. The function of HtrA4 under normal conditions may be redundant, however, it is possible that HtrA4 may be activated in a pathological situation. Similar to human HtrA4, mouse HtrA4 was also expressed in the placenta. In the placenta of patients with pre-eclampsia, the protein expression of HtrA4 was increased (17). In addition, HtrA4 is a target gene of the placental transcription factor, glial cells missing 1 (20). HtrA4 represses the fusogenic activity of syncytin-1 and promotes trophoblast invasion (20). It is possible that HtrA4 works in association with the other HtrA family members. HtrA1 was upregulated in the mouse model of arthritis, and contributed to cartilage degradation (8).
Another member of the HtrA family, HtrA2, was increased in the rat testis in response to experimental cryptorchidism (21). The mouse model described in the present study may be useful in studying the roles of HtrA4 in pathogenesis $(17,19,20)$.

In the present study, it was observed that the mouse HtrA4 protein is specifically expressed in the endothelial cells of coronary vessels. However, a loss of HtrA4 failed to induce abnormalities in the morphology and function of the heart. The protein structure of HtrA4 is very similar to that of HtrA1, which is highly expressed in endothelial cells, smooth muscle cells and perivascular fibroblasts (22). In the vascular system, HtrA1 regulates transforming growth factor- $\beta$ (TGF- $\beta$ ) signaling, and is involved in the pathogenesis of cerebral autosomal recessive arteriopathy with subcortical infarcts and leukoencephalopathy (23). The N-termini of the HtrA1 and HtrA4 proteins contain predicted cleavable signal peptides and a fragment of insulin growth factor-binding protein (IGFBP)7 (15). IGFBP and kinase interaction domains in HtrA1 and HtrA4 revealed a similarity to follistatin, which is a potent antagonist of TGF- $\beta$ signaling (24-26). In addition, HtrA 1 inhibited TGF- $\beta$ signaling under a variety of cellular conditions (27). Therefore, HtrA4 may also interact with the TGF- $\beta$ family of proteins, although its function may be compensated by HtrA1.

Taken together, the conditional null HtrA4 allele in mice was generated and validated by effective Cre excision, which led to the loss of transcription and protein expression levels of HtrA4. This novel mouse line provides opportunities to address the tissue and cell type-specific roles of HtrA4 under different physiological and pathological conditions.

\section{Acknowledgements}

The present study was funded by the Rosebay Medical Foundation and Yale Medical School Dean's Research Fund, the National Natural Science Foundation of China (grant no. 81370269), and the Shandong Taishan Scholarship. The authors would like to thank Professor Frank Giordano, Dr Yan Huang and Mr. Steve Viviano of Yale University for their scientific input and technical assistance.

\section{References}

1. Strauch KL and Beckwith J: An Escherichia coli mutation preventing degradation of abnormal periplasmic proteins. Proc Natl Acad Sci USA 85: 1576-1580, 1988.

2. Pallen MJ and Wren BW: The HtrA family of serine proteases. Mol Microbiol 26: 209-221, 1997.

3. Clausen T, Southan C and Ehrmann M: The HtrA family of proteases: Implications for protein composition and cell fate. Mol Cell 10: 443-455, 2002.

4. Zurawa-Janicka D, Skorko-Glonek J and Lipinska B: HtrA proteins as targets in therapy of cancer and other diseases. Expert Opin Ther Targets 14: 665-679, 2010.

5. Vande Walle L, Lamkanfi M and Vandenabeele P: The mitochondrial serine protease HtrA2/Omi: An overview. Cell Death Differ 15: 453-460, 2008.

6. Dewan A, Liu M, Hartman S, Zhang SS, Liu DT, Zhao C, Tam PO, Chan WM, Lam DS, Snyder M, et al: HTRA1 promoter polymorphism in wet age-related macular degeneration. Science 314: 989-992, 2006

7. Grau S, Richards PJ, Kerr B, Hughes C, Caterson B, Williams AS, Junker U, Jones SA, Clausen T and Ehrmann M: The role of human HtrA1 in arthritic disease. J Biol Chem 281: 6124-6129, 2006. 
8. Tsuchiya A, Yano M, Tocharus J, Kojima H, Fukumoto M, Kawaichi M and Oka C: Expression of mouse HtrA1 serine protease in normal bone and cartilage and its upregulation in joint cartilage damaged by experimental arthritis. Bone 37: 323-336, 2005.

9. Chien J, Staub J, Hu SI, Erickson-Johnson MR, Couch FJ, Smith DI, Crowl RM, Kaufmann SH and Shridhar V: A candidate tumor suppressor HtrA1 is downregulated in ovarian cancer. Oncogene 23: 1636-1644, 2004.

10. Baldi A, De Luca A, Morini M, Battista T, Felsani A, Baldi F, Catricalà $\mathrm{C}$, Amantea $\mathrm{A}$, Noonan DM, Albini A, et al: The HtrA1 serine protease is down-regulated during human melanoma progression and represses growth of metastatic melanoma cells. Oncogene 21: 6684-6688, 2002.

11. Park HJ, Seong YM, Choi JY, Kang S and Rhim H: Alzheimer's disease-associated amyloid beta interacts with the human serine protease HtrA2/Omi. Neurosci Lett 357: 63-67, 2004.

12. Bakay M, Zhao P, Chen J and Hoffman EP: A web-accessible complete transcriptome of normal human and DMD muscle. Neuromuscul Disord 12 (Suppl 1): S125-S141, 2002.

13. Ross OA, Soto AI, Vilariño-Güell C, Heckman MG, Diehl NN Hulihan MM, Aasly JO, Sando S, Gibson JM, Lynch T, et al: Genetic variation of Omi/HtrA2 and Parkinson's disease. Parkinsonism Relat Disord 14: 539-543, 2008.

14. Zhu F, Jin L, Luo TP, Luo GH, Tan Y and Qin XH: Serine protease HtrA1 expression in human hepatocellular carcinoma. Hepatobiliary Pancreat Dis Int 9: 508-512, 2010.

15. Clausen T, Kaiser M, Huber R and Ehrmann M: HTRA proteases: Regulated proteolysis in protein quality control. Nat Rev Mol Cell Biol 12: 152-162, 2011

16. Ketteler R, Sun Z, Kovacs KF, He WW and Seed B: A pathway sensor for genome-wide screens of intracellular proteolytic cleavage. Genome Biol 9: R64, 2008.

17. Inagaki A, Nishizawa $\mathrm{H}$, Ota S, Suzuki M, Inuzuka $\mathrm{H}$, Miyamura $\mathrm{H}$, Sekiya $\mathrm{T}$, Kurahashi $\mathrm{H}$ and Udagawa $\mathrm{Y}$ : Upregulation of $\mathrm{HtrA} 4$ in the placentas of patients with severe pre-eclampsia. Placenta 33: 919-926, 2012.
18. Soriano P: Generalized lacZ expression with the ROSA26 Cre reporter strain. Nat Genet 21: 70-71, 1999.

19. Chien J, Campioni M, Shridhar V and Baldi A: HtrA serine proteases as potential therapeutic targets in cancer. Curr Cancer Drug Targets 9: 451-468, 2009.

20. Wang LJ, Cheong ML, Lee YS, Lee MT and Chen H: High-temperature requirement protein A4 (HtrA4) suppresses the fusogenic activity of syncytin-1 and promotes trophoblast invasion. Mol Cell Biol 32: 3707-3717, 2012.

21. Hayashi T, Yoshida S, Yoshinaga A, Ohno R, Ishii N and Yamada T: HtrA2 is up-regulated in the rat testis after experimental cryptorchidism. Int J Urol 13: 157-164, 2006.

22. Liu J, Dong F and Hoh J: Loss of HtrA1-induced attenuation of TGF- $\beta$ signaling in fibroblasts might not be the main mechanism of CARASIL pathogenesis. Proc Natl Acad Sci USA 112: E1693, 2015.

23. Hara K, Shiga A, Fukutake T, Nozaki H, Miyashita A, Yokoseki A, Kawata H, Koyama A, Arima K, Takahashi T, et al: Association of HTRA1 mutations and familial ischemic cerebral small-vessel disease. N Engl J Med 360: 1729-1739, 2009.

24. Kato MV: A secreted tumor-suppressor, mac25, with activin-binding activity. Mol Med 6: 126-135, 2000.

25. Nakamura T, Takio K, Eto Y, Shibai H, Titani K and Sugino H: Activin-binding protein from rat ovary is follistatin. Science 247 : 836-838, 1990.

26. Hu SI, Carozza M, Klein M, Nantermet P, Luk D and Crowl RM: Human HtrA, an evolutionarily conserved serine protease identified as a differentially expressed gene product in osteoarthritic cartilage. J Biol Chem 273: 34406-34412, 1998.

27. Oka C, Tsujimoto R, Kajikawa M, Koshiba-Takeuchi K, Ina J, Yano M, Tsuchiya A, Ueta Y, Soma A, Kanda H, et al: HtrA1 serine protease inhibits signaling mediated by Tgfbeta family proteins. Development 131: 1041-1053, 2004. 